\title{
Alkaloid Levels in Reed Canarygrass Grown on Wet Meadows in British Columbia
}

W. MAJAK, R.E. MCDIARMID, A.L. van RYSWYK, K. BROERSMA, AND S.G. BONIN

\author{
Abstract
}

Hordenine, gramine, and 5-methoxy-N-methyltryptamine (5MMT) were identified as the major basic alkaloids in reed canarygrass grown on wet meadows in Interior British Columbia. The concentrations of these anti-quality constituents, determined sequentially at four field locations, were exceptionally low compared with levels found for reed canarygrass grown under growth room conditions. Under field conditions, for example, 5MMT levels did not exceed $250 \mu \mathrm{g} / \mathrm{g}$ (dry wt), whereas a peak level of $4,250 \mu \mathrm{g} / \mathrm{g} 5 \mathrm{MMT}$ was recorded from the growth room. Depressed alkaloid levels under wet meadow field conditions were observed in all varieties tested including two experimental varieties, one registered variety, and a commercial type. Low alkaloid levels on wet meadows appeared to coincide with fewer types of alkaloids: 5-methoxy-N, N-dimethyltryptamine (5DMT) was not detected under field conditions but it was present in all reed canarygrass samples analyzed from the growth room. Field applications of fertilizer (NPK) appeared to have marginal effects on alkaloid levels. On wet meadows the trends indicated that gramine and 5MMT concentrations increased toward the end of the growing season, but low total alkaloid levels were still maintained. The factor of soil moisture stress is reviewed in relation to alkaloid levels in reed canarygrass. Recently developed thin layer chromatography (TLC) scanning procedures were used to determine concentrations of gramine and 5MMT. New TLC fluorescence methods were devised for the quantitative determination of hordenine and 5DMT in reed canarygrass.

In the British Columbia Interior, large wet meadow areas composed primarily of low-yielding native sedge-grass mixtures are being reseeded to reed canarygrass (Phalaris arundinacea L.) (van Ryswyk et al. 1974; van Ryswyk and Bawtree 1971). Organic soil meadows and bogs in particular are becoming a principal source of reed canarygrass hay in the central Cariboo region. The aftermath is grazed by cattle in late summer and fall. Ruminants grazing reed canarygrass can be debilitated, however, when the forage contains high concentrations of basic alkaloids. Marten et al. (1976) demonstrated that average daily gains were reduced and the incidence of diarrhea increased when sheep and cattle grazed high-alkaloid $(0.19$ to $0.68 \%$ dry wt) as compared with low-alkaloid $(0.06$ to $0.32 \%)$ genotypes. The poor performance related in part to differences in reed canarygrass palatability which was highly negatively correlated with the total basic alkaloid concentration (Marten et al. 1973; Simons and Marten 1971). The effects of high alkaloid diets were reversible, however, and permanent detrimental disorders were not observed (Marten et al. 1976). In contrast, the basic

\footnotetext{
Majak. Mcl barmid, fan Ryswyk and Broersma are plant bichemist, research assistant.

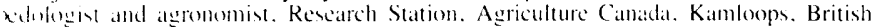
(i) lombia: Bonin is orass breeder. Research Station. Agriculture Canada. Beaverlodge. vilectal Contribution No. 275. Agriculture Canada.

Manustipt receiled lehruary $-7.107 x$
}

alkaloids of Phalaris aquatica ( $P$. tuberosa) have been linked to the occurrence of acute "phalaris staggers" in sheep (Gallagher et al. 1964; Rendig et al. 1976). Clearly the phalaris alkaloids can depress animal performance and therefore they are considered to be anti-quality constituents.

The above studies have emphasized the anti-quality effects of four indole alkaloid constituents: N,N-dimethyltryptamine (DMT), 5-methoxy-DMT (5DMT), gramine and 5-methyl6-methoxy-1,2,3,4-tetrahydro- $\beta$-carboline. The role of two additional alkaloids, 5-methoxy-N-methyltryptamine (5MMT) and hordenine (a phenolic alkaloid) has been obscured in part by a lack of sensitive and specific methodology (Coulman et al. 1977). Similarly, technical difficulties have discouraged a quantitative study of the concomitant variation of individual reed canarygrass alkaloids. The presence of tryptamine alkaloids, for example, interferes with the colorimetric determination of gramine and/or hordenine ${ }^{1}$ (Woods and Clark 1971). Specific fluorometric scanning methods have been developed recently for the quantitative determination of reed canarygrass indole alkaloids (Majak and Bose 1977; Majak et al. 1978). In the present work we have expanded the procedures to accommodate the simultaneous determination of 5DMT and $5 \mathrm{MMT}$, and a specific fluorometric scanning procedure has been developed for the quantitative determination of hordenine as the dansyl derivative. Accordingly, it was feasible to (a) monitor sequentially the specific alkaloid levels of reed canarygrass stands on four Interior Organic meadows in B.C . (b) to examine some variety differences with respect to individual alkaloid levels and (c) to compare the wet meadow field values to growth room levels where much higher alkaloid concentrations were produced. In effect, this survey will reveal the current status of anti-quality components in reed canarygrass grown on B.C. Interior Organic meadows.

\section{Materials and Methods}

\section{Experimental Sites and Varieties}

Reed canarygrass stands were located at Strachan I ake (elev. 1,460 $\mathrm{m})$. Watch Lake $(1,190 \mathrm{~m})$, Hopkinson's Meadow $(1,250 \mathrm{~m})$ near LacLeJeune, 1.34 Mile House $(750 \mathrm{~m})$ and Horse Lake $(930 \mathrm{~m})$. These sites were situated over a distance of $200 \mathrm{~km}$ between Kamloops and Williams Lake. The soils were classified as Mesisols (Hemist) for the first three meadows, Humisol (Saprist) for the fourth, and Humic Gleysol (Aquoll) for the fifth, according to the system of the Canada Soil Survey Committee (1974) and the U.S. soil taxonomy system (U.S. Dep. Agr. 1975)

Two experimental varieties, NRG 721 and NRG 741 ("low tryptamine" and "high tryptamine" respectively) and a registered

Peronat commtanication. D I. Woods. Agriculture Canada Saskatoon, Sask 
variety, Castor, were established at Hopkinson's Meadow and under growth room conditions in Kamloops. A commercial seedlot of known origin was also cultured in the growth room. The origins of the commercial seedlots established on the remaining meadows were unknown. A standard peat-sand mix in pots (B.C. Ministry of Agr. 1972), a $21^{\circ} \mathrm{C}$ room and soil temperature and a 13 -hr photoperiod were used in the growth room. The light source was fluorescent lamps (Vita-Lite, Duro-Test Corp.) generating approximately $150 \mathrm{cal} / \mathrm{cm}^{2} /$ day at the average height of the grass.

\section{Plant Samples}

Composite samples of reed canarygrass ( $100 \mathrm{~g}$ fresh wt unclipped, aerial portions) were harvested sequentially from a $3 \times 8.4-\mathrm{m}$ plot at aach meadow, transported on ice, and frozen. A measure of the variability within a plot was obtained by dividing each plot into $1.5 \times$ -. $1 \mathrm{~m}$ quarters and a $25 \mathrm{~g}$ fresh wt sample from each quarter was collected for alkaloid analysis. Each frozen sample was chopped finely in a coldroom $\left(2^{\circ} \mathrm{C}\right)$, a 10 -g subsample was tared for extraction, and duplicate subsamples were used for dry wt determinations. Since the extraction procedure was complete (as evidenced by chromatographic checks of serial extractions) and since there was close agreement between duplicate extractions $(< \pm 5 \%$ variation with respect to duplicate alkaloid determinations), a single extraction of each sample was found to be sufficient.

\section{Quantitative Determinations}

For gramine, 5MMT, and 5DMT determinations, a frozen 10-g portion was extracted, fractionated, and two-thirds of the final chloroform extract was washed with water, concentrated to dryness, and redissolved in $0.25 \mathrm{~m} t 2$-methoxy-ethanol (extract A) as described previously (Majak and Bose 1977). For hordenine determinations the water wash was omitted from the remaining one-third portion of the chloroform extract, and this was concentrated to dryness and redissolved in $0.5 \mathrm{~m} t$ 2-methoxy-ethanol (extract $\mathrm{B}$ ).

Microliter aliquots of extract A were applied to precoated TLC plates for quantifying gramine and 5MMT by fluorometric scanning (Majak and Bose 1977; Majak et al. 1978). Samples which contained both 5MMT and 5DMT were resolved in a new chromatographic system which permitted the quantitative determination of both compounds on a single plate by acid-induced fluorescence as follows: A silica gel 60 plate (E. Merck, Darmstadt, EM No. 576.3) was exposed to $\mathrm{HCl}$ fumes for $15 \mathrm{~min}$. Following the exposure, aliquots of extract $A$ and reference standards were applied, the plate was developed in isopropanol:ethyl acetate:conc. $\mathrm{HCl}, 60: 15: 1$, and dried in a fume hood for $10 \mathrm{~min}$ in a uniform current of air away from direct light. 5 MMT $\left(\mathrm{R}_{f} 0.32\right)$ and 5DMT $\left(\mathrm{R}_{f} 0.10\right)$ were located by their bright yellow fluorescence under short-wave ultraviolet light and immediately scanned at right angles to the solvent flow using the fluorometer conditions described previously (Majak and Bose 1977). When an authentic sample of 5DMT was subjected to the above fractionation procedure, the compound was recovered in $95 \%$ yield.

$T$ " procedure for hordenine determination was as follows: Extract B. - ( ) $\mu \mathrm{t}$, was concentrated to dryness in a $0.3 \mathrm{~m} t$ Reacti-vial and securely capped using a Tuf-Bond disc (Pierce Chem. Co. No. $12712)$. The dried residue was dissolved by injecting $100 \mu t$ acetone and this was followed by injections of $100 \mu t 0.1 N \mathrm{NaHCO}_{3}$ and 100 $\mu$ t dansyl chloride reagent (prepared fresh daily by dissolving $15 \mathrm{mg}$ dansyl chloride in $5 \mathrm{ml}$ acetone and stored in the refrigerator). The vial was heated for $30 \mathrm{~min}$ at $30^{\circ} \mathrm{C}$ in the dark, then chilled in a freczer before applying microliter aliquots to a silica gel 60 plate (EM No. $57(.3)$ with adjacent dansyl-hordenine standards. The TLC plate was developed in freshly prepared PENE solvent (Majak et al. 1978) and dried for $60 \mathrm{~min}$ in a fume hood. minimizing exposure to light. The dansyl-hordenine spots $\left(\mathrm{R}_{f} 0.75\right)$, located by their yellow fluorescence in short-wave ultraviolet light, were scanned at right angles to the solvent flow using the fluorometer conditions described previously (Majak et al. 1978) but employing a No. 8 (Turner No. 110-817) secondary filter. The relationship between peak height and dansylhordenine concentration was linear over the range 0.05 to $0.5 \mu \mathrm{g}$ hordenine. When an authentic sample of hordenine $(100 \mu \mathrm{g})$ was ded to the crude plant extract, the above procedure recovered hordenine in $97 \%$ yield. With samples containing high levels of 5 MMT $(>500 \mu \mathrm{g} / \mathrm{g}$ dry wt) a 10 - to 20 -fold dilution of extract B was required to ensure the presence of excess dansyl reagent.

\section{Results and Discussion}

\section{Alkaloid Profiles}

The alkaloid screening experiments conducted during 1977 confirmed our previous observation (Majak and Bose 1977) that gramine. hordenine and 5MMT are the primary basic alkaloids in recd canarygrass grown on Organic soil meadows in Interior British Columbia. The alkaloid profile of reed canarygrass grown on the Gleysolic soil meadow (Horse Lake) was similar (Table 1), and 5MMT appears to be the major component of the unidentified tryptamines reported for the Thompson River madow (Parmar and Brink 1976). Growth room samples contained an additional alkaloid. identified as 5DMT on the basis of fluorescence and co-chromatography with authentic 5DMT in a number of solvent systems on cellulose and silica gel TLC. Tetrahydro- $\beta$-carboline derivatives and DMT were not detected in the present studies.

Table 1. Mean concentrations ( $\mu \mathrm{g} / \mathrm{g}$ dry wt) for $5 \mathrm{MMT}$, gramine and hordenine in reed canarygrass subcomposite field samples.

\begin{tabular}{|c|c|c|c|c|c|}
\hline \multirow[b]{2}{*}{ Sitc } & \multirow{2}{*}{$\begin{array}{c}\text { Collection } \\
\text { date } \\
1977\end{array}$} & \multirow{2}{*}{$\begin{array}{l}\text { Plot } \\
\text { no. }\end{array}$} & \multicolumn{3}{|c|}{ Alkaloid } \\
\hline & & & 5MMT & Gramine & Hordenine \\
\hline Strachan L. & Aug. II & 1 & $3.3 \mathrm{a}^{\prime}$ & $115 \mathrm{a}$ & $340 \mathrm{~b}$ \\
\hline $1.3+$ Mile & Jul. 21 & 1 & $29 a$ & $62 a$ & $103 c$ \\
\hline \multirow[t]{2}{*}{ Watch L. } & June 21 & 1 & $14 a$ & $77 a$ & $190 \mathrm{~b}$ \\
\hline & & 2 & $29 a$ & $80 \mathrm{a}$ & $37.3 \mathrm{a}$ \\
\hline \multirow[t]{2}{*}{ Horse L. } & June 21 & 1 & $24 a$ & $67 a$ & $359 a$ \\
\hline & & 2 & $38 a$ & $52 \mathrm{a}$ & $253 \mathrm{~b}$ \\
\hline \multicolumn{2}{|c|}{ Means of experimental plots } & & $28 \mathrm{C}$ & $75 \mathrm{~B}$ & $253 \mathrm{~A}$ \\
\hline
\end{tabular}

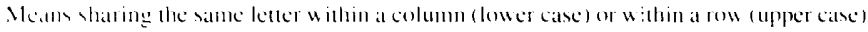

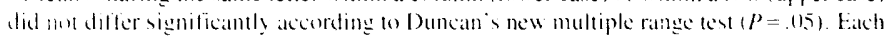
lliesn is derised from the alkaloid concentrations in four subcomposite samples. at

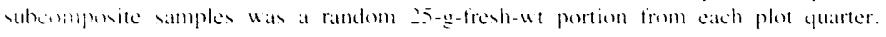

Parmar and Brink (1976) suggested that the tryptamines of reed canarygrass could be implicated in a pasture-mediated form of bovine pulmonary emphysema prevalent throughout Interior British Columbia and the intermountain states. Intraruminal administration of indole derivatives such a tryptophan and indole acetic acid will induce pulmonary emphysema and edema in cattle and the active metabolite. dissimilated by ruminal microorganisms, has been identified as 3-methylindole (Carlson et al. 1972). Yokoyama and Carlson (1974), however. showed that for a number of indole compounds. including tryptamine and 5-hydroxytryptamine. microbial degradation to :-methylindole does not occur, and whether indoles such as 5MMT. 5DMT. or gramine are potential substrates for 3methylindole formation remains to be seen.

\section{Variability in Alkaloid Concentration}

Alkaloid identification at each site was followed by a scrics of replicate determinations to give an indication of the variability in alhaloid concentration within each experimental plot. A h:ow ledge of the potential variation within a site would provide a hasis for comparing sequential alkaloid values. Table I lists the means for 5MMT, gramine and hordenine derived from subcomposite samples at three Organic and one Gleysolic meadow. A high degree of variability is indicated within each experimental plot and, in the case of hordenine, between replicate plots at two sites (Table 1). The variability could be 


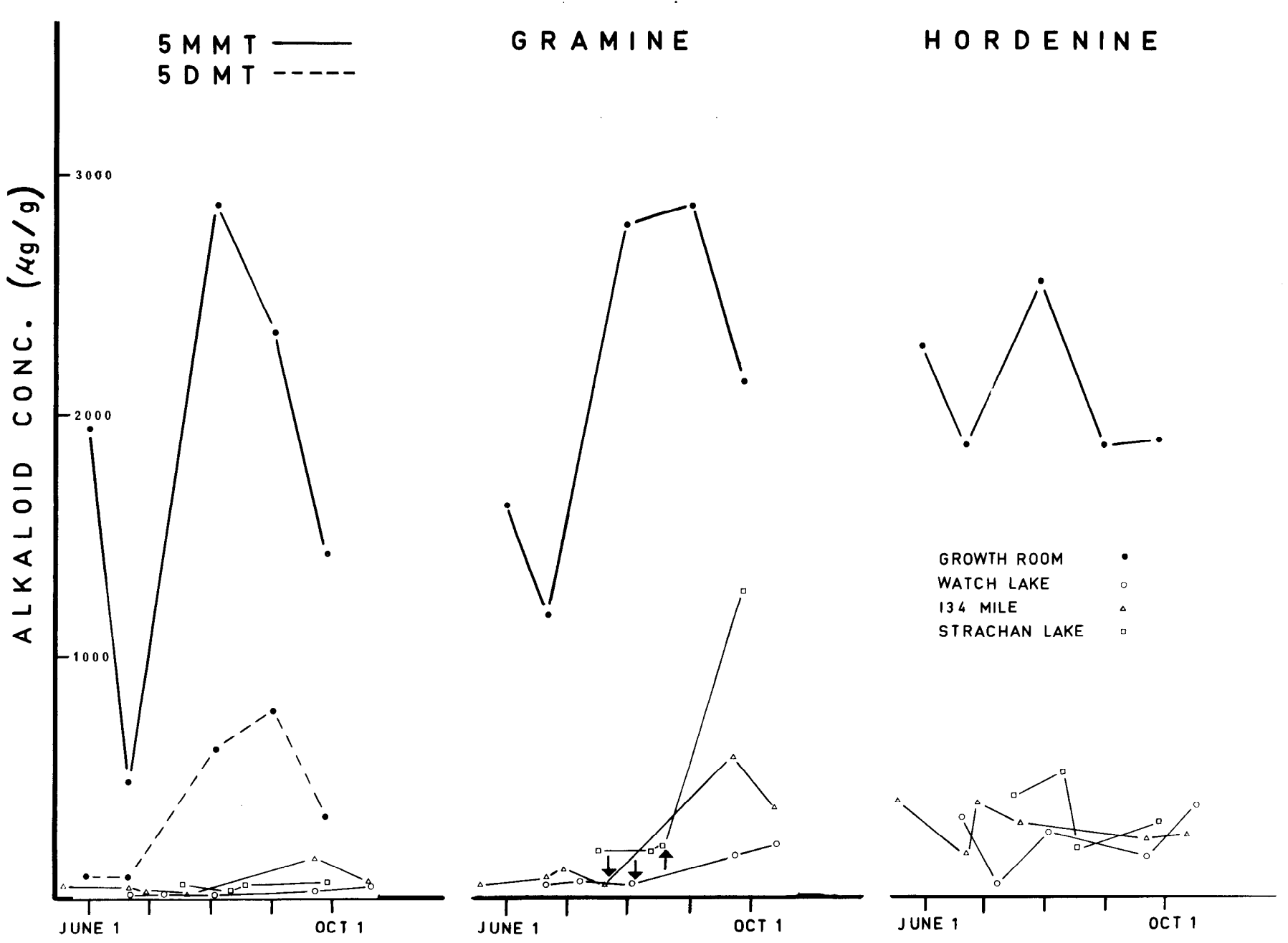

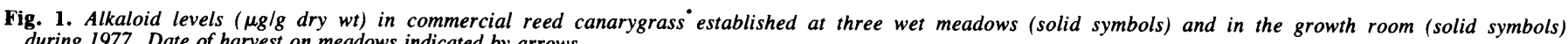
during 1977. Date of harvest on meadows indicated by arrows.

related to differences in plant nutrient uptake as affected by variations in depth to water table and inherent soil fertility differences within plots. ${ }^{2}$

The gramine and hordenine values reported in Table 1 are exceptionally low in comparison to previously reported figures. A survey of reed canarygrass introductions conducted by Coulman et al. (1976), for example, yielded mean gramine concentrations of $2,090 \mu \mathrm{g} / \mathrm{g}$ dry wt (range 40 to $6,910 \mu \mathrm{g} / \mathrm{g}$ ) and $2,200 \mu \mathrm{g} / \mathrm{g}$ (range 170 to $11,510 \mu \mathrm{g} / \mathrm{g}$ ) over a 2-year study. On the other hand, clones selected for low gramine yielded average values of $190 \mu \mathrm{g} / \mathrm{g}$ gramine and $1,220 \mu \mathrm{g} / \mathrm{g}$ hordenine (Coulman et al. 1977), but these values are still in excess of our means shown in Table 1. Summation of the individual alkaloid values in Table 1 reflect a total basic alkaloid content of 0.02 to $0.05 \%$, a range that would be considered lower than previously reported low alkaloid levels (Marten et al. 1976; Hovin and Marten 1975). The low 5MMT values in Table 1 are in agreement with our previous analyses of reed canarygrass samples from Organic meadows in 1976 when the observed range was 14 to $67 \mu \mathrm{g} / \mathrm{g}$ (Majak and Bose 1977).

\section{Changes in Alkaloid Levels During the Growing Season}

The next step was to sequentially monitor alkaloid levels on meadow sites and to observe possible fluctuations during the growing season. Figure 1 illustrates the results of this study at three meadows where reed canarygrass had been established from commercial seed. Low concentrations of 5MMT, usually
$<60 \mu \mathrm{g} / \mathrm{g}$ dry wt, were maintained throughout the growing season. Low gramine levels $(<125 \mu \mathrm{g} / \mathrm{g}$ at Watch Lake and 134 Mile) on the other hand were elevated in the regrowth herbage after harvesting but a similar response was not observed from hordenine. Excluding the September gramine value for Strachan, the trend of seasonal plot means was hordenine < gramine$>5 \mathrm{MMT}$ and a similar trend was observed at Hopkinson's Meadow (Fig. 2). Depressed values for 5MMT, gramine, and hordenine were recorded at Hopkinson's Meadow in all varieties tested (Fig. 2). Under growth room conditions, however, not only were the levels of 5MMT, gramine, and hordenine substantially elevated but 5DMT made an appearance for the first time (Fig. 1 and 2). Higher 5DMT levels were observed in the experimental variety NRG 741 and in the commercial type (Fig. 1 and 2), as compared with NRG 721 and Castor (not illustrated), which gave peak 5DMT values of 300 $\mu \mathrm{g} / \mathrm{g}$ and $150 \mu \mathrm{g} / \mathrm{g}$, respectively. Summation of the peak alkaloid levels produced under growth room conditions gave a total alkaloid content of $0.84 \%$ for the commercial type (Fig. 1) and $0.96 \%$ for the experimental variety NRG 741 (Fig. 2). These values could be considered debilitative (Marten et al. 1976) but not excessive since Simons and Marten (1971) have reported a total basic alkaloid range of 0.01 to $2.75 \%$ for reed canarygrass clones. Therefore the outstanding feature recorded in Figures 1 and 2 is not so much the increased level in the growth room environment as the suppressed level and fewer types of alkaloids in wet meadow field situations. 


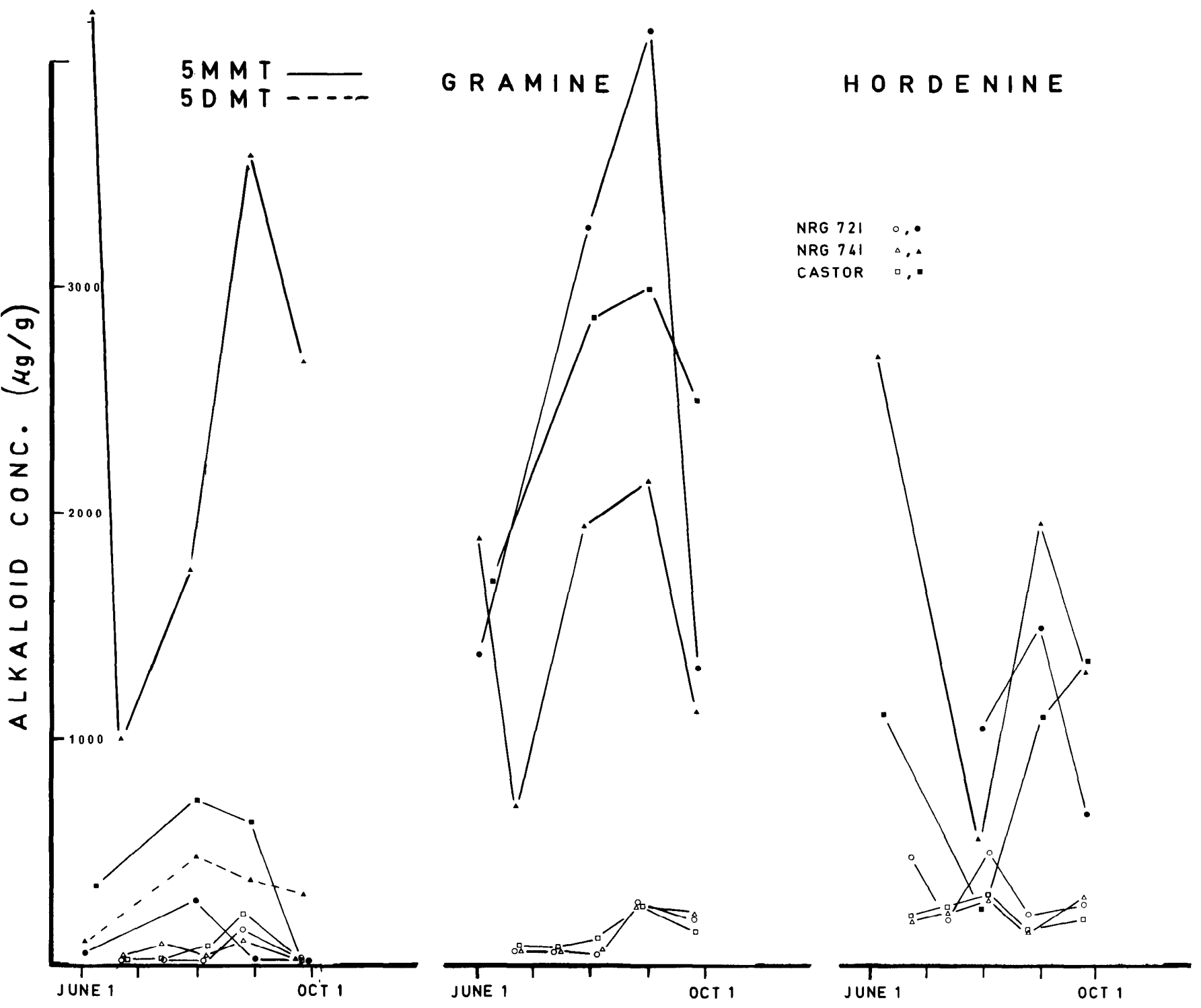

Fig. 2. Alkaloid levels ( $\mu \mathrm{g} / \mathrm{g}$ dry wt) in three varieties of reed canarygrass at Hopkinson's meadow (open symbols) and in the growth room (solid symbols) during 1977.

The low alkaloid accumulation on wet meadow sites cannot be attributed exclusively to deficiencies in soil fertility. In fact, Marten et al. (1974) demonstrated higher alkaloid levels in reed canarygrass grown on infertile peat as compared with fertile mineral soils. Where nutrient amendments have elevated alkaloid levels in reed canarygrass, the changes have been relatively small. A six-fold increase in $\mathrm{NH}_{1} \mathrm{NO}_{3}$ application (from 50 to $300 \mathrm{~kg} / \mathrm{ha} \mathrm{N}$ ) for example, produced only a $13 \%$ increase in total tryptamines (Parmar and Brink 1976). Similarly, application of complete fertilizer and additional nitrogen $(240 \mathrm{~kg} / \mathrm{ha} \mathrm{N})$ to an infertile peat soil resulted in a minor change in total alkaloids as the level increased from 0.05 to $0.07 \%$ (Marten et al. 1974). Furthermore, we compared alkaloid levels in reed canarygrass growing on fertilized wet meadow plots which had received an original application of $150 \mathrm{~kg} / \mathrm{ha} \mathrm{N}\left(\mathrm{NH}_{4} \mathrm{NO}_{3}\right), 100 \mathrm{~kg} / \mathrm{ha} \mathrm{P}$, and $200 \mathrm{~kg} / \mathrm{ha} \mathrm{K}$, followed by mid-season application of 150 $\mathrm{kg} / \mathrm{ha} \mathrm{N}$. The results indicated that only in 6 out of 30 cases during the growing season was an alkaloid concentration at least doubled in comparison to reed canarygrass samples from unfertilized plots. For example, on fertilized plots 5MMT and gramine increased to maximum levels of $164 \mu \mathrm{g} / \mathrm{g}$ and 1,806 $\mu \mathrm{g} / \mathrm{g}$, respectively (Strachan Lake, Sept. 29); and hordenine increased to $625 \mu \mathrm{g} / \mathrm{g}$ (Watch Lake, June 21). These levels are still well below the high-alkaloid range generated in the growth room.

Marten (1973) observed that increased alkaloid levels in reed canarygrass are produced in response to moisture stress and concluded that of all the environmental parameters tested in relation to alkaloid accumulation the most critical was soil moisture availability to plants. The corollary suggests, therefore, that in reed canarygrass alkaloid biosynthesis could be diminished under optimal moisture conditions. A continuous store of soil water available to plants under negligible soil moisture tension typifies the saturation conditions of Organic soil meadows. In this situation one would expect reed canarygrass to be under minimal moisture stress. In the absence of rainfall in late summer and early fall the depth to water table on wet meadows can increase, but the availability of water is maintained usually by upward capillary movement. Trends reflect increasing indole alkaloid (5MMT and gramine) concentrations toward late summer (Fig. 1 and 2) and whether this is in response to an increase in moisture stress remains to be seen. Previously, we reported a range of values for gramine (280-780 $\mu \mathrm{g} / \mathrm{g}$ in the Castor variety established on Solonetzie soil (Majak et al. 1978). This saline situation features a soil moisture stress situation for plants that could be reflected in the 
elevated alkaloid levels. Further research will reveal whether moisture availability can control alkaloid accumulation in reed canarygrass.

In conclusion, factors which could enhance alkaloid biosynthesis in the growth room should be considered and these include reduced light energy and rapid vegetative regrowth in response to clipping. Artificial shading experiments have demonstrated a dramatic rise in DMT and 5DMT concentrations when $P$. tuberosa was exposed to $<34 \%$ full sunlight (Moore et al. 1967). Similarly. total basic alkaloid concentration in reed canlarygrass increased by over $50 \%$ in response to shading (Marten 1973). Light energy in our growth room was measured as approximately $150 \mathrm{cal} / \mathrm{cm}^{2} /$ day: or $25 \%$ of full sunlight on a summer day at latitudes where meadows were studied". Clipping reed canary grass every 2 weeks produced a sharp increase in indole alkaloid levels as compared to levels in free growth tissue (Woods and Clark 1971). Growth room samples in our experiments were harvested approximtely every 5 weeks and a similar response resulting in high alkaloid pooduction is not unlikely.

Peronal communication, R.J. Williams. B.C. Ministry of the Environment. Kamloops. K.timloous. B.C.

\section{Literature Cited}

British Columbia Ministry of Agriculture. 1972. Small Greenhouses, Construction and Management. p. 11. Victoria, B.C.

Canada Soil Survey Committee. 1974. The System of Soil Survey for Canada. Information Canada, Ottawa

Carlson, J.R., M.T. Yokoyama, and E.O. Dickinson. 1972. Induction of pulmonary edema and emphysema in cattle and goats with 3-methylindole. Science 176:298-299.

Coulman, B.E., D.L. Woods, and K.W. Clark. 1976. Identification of low alkaloid genotypes of reed canarygrass. Can. J. Plant Sci. 56:837-845.

Coulman, B.E., D.L. Woods, and K.W. Clark. 1977. Distribution within the plant, variation with maturity and heritability of gramine and hordenine in reed canarygrass. Can. J. Plant Sci. 57:771-777.

Gallagher, C.H., J.H. Koch, R.M. Moore, and J.D. Steel. 1964. Toxicity of Phalaris tuberosa for sheep. Nature 204:542-545.
Hovin, A.W., and G.C. Marten. 1975. Distribution of specific alkaloids in reed canarygrass cultivars. Crop Sci. 15:705-707.

Majak, W., and R.J. Bose. 1977. Further characterization and quantitative determination of 5-methoxy-N-methyltriptamine in Phalaris arundinacea. Phytochemistry 16: 749-752.

Majak, W., R.E. McDiarmid, and R.J. Bose. 1978. TLC luminescence of gramine and related indole alkaloids in Phalaris arundinacea. Phytochemistry 17:30/-303.

Marten, G.C. 1973. Alkaloids in reed canarygrass. p. 23. In: Anti-quality Components of Forages. A.G. Matches (ed.), Spec. Pub. 4. Crop Sci. Soc. Amer., Madison, Wisc.

Marten, G.C., R.F. Barnes, A.B. Simons, and F.J. Wooding. 1973. Alkaloids and palatability of Phalaris arundinacea $\mathrm{L}$. grown in diverse environments. Agron. J. 65:199-201.

Marten, G.C., A.B. Simons, and J.R. Frelich. 1974. Alkaloids of reed canarygrass as influenced by nutrient supply. Agron. J. 66:363-368.

Marten, G.C., R.M. Jordan, and A.W. Hovin. 1976. Biological significance of reed canarygrass alkaloids and associated palatability variation to grazing sheep and cattle. Agron. J. 68:909-914.

Moore, R.M., J.D. Williams, and J. Chia. 1967. Factors affecting concentrations of dimethylated indole alkylamines in Phalaris tuberosa L. Aust. J. Biol. Sci. 20:1131-1140.

Parmar, S.S., and V.C. Brink. 1976. Tryptamine levels in pasturage implicated in bovine pulmonary emphysema. Can. J. Plant Sci. 56:175-184.

Rendig, V.V., D.W. Cooper, J.R. Dunbar, C.M. Lawrence, W.J. Clawson, R.B. Bushnel, and E.A. McComb. 1976. Phalaris "staggers" in California. California Agr. June issue, p. 8-10.

van Ryswky, A.L., and A.H. Bawtree. 1971. Management and Improvement of Meadows on Organic Soils of British Columbia. B.C. Ministry of Agriculture, Victoria, B.C. Ilp.

van Ryswyk, A.L., W.L. Pringle, and J.H. Neufeld. 1974. Response of reed canarygrass grown on ten British Columbia Organic soils to N, P, K and lime. Can. J. Soil Sci. 54:273-285.

Simons, A.B., and G.C. Marten. 1971. Relationship of indole alkaloids to palatability of Phalaris arundinacea L. Agron. J. 63:915-919.

U.S. Dep. Agr. 1975. Soil Taxonomy. Agr. Handbk. No. 436, Soil Conserv. Serv. U.S. Dep. Agr.

Woods, D.L., and K.W. Clark. 1971. Genetic control and seasonal variation of some alkaloids in reed canarygrass. Can J. Plant Sci. 51:323-329.

Yokoyama, M.T., and J.R. Carlson. 1974. Dissimilation of tryptophan and related indolic compounds by ruminal microorganisms, in vitro. Applied Microbio. 27:540-548. 